As density docreased, both primary lines became less bright, and the contrast between them increased. At $0 \cdot 17 \mathrm{~g} / \mathrm{cm}^{3}$, the air line was still distinct; but the butane line had almost disappeared. One should not attach great weight at the moment to this slender evidence; but it is at least consistent with the foregoing ideas, which may also be relevant in comparing explosive and inert powders.

An important part of the earlier ovidence collected by Blackburn and Seely was the persistence of light in a shocked inert powder which had been highly evacuated. We have tried to supplement this by experiments on both inert and explosive powders in which the initial pressure was raised to 100 or $200 \mathrm{~atm}$. The argument here is that one would expect the shock pressure ratio and thus the gas pocket temperatures to be much reduced ${ }^{3}$. Fig. 3 shows the experimental arrangement and a typical trace. The first plastic charge transmitted detonation through the 'Perspex' barrier to the first PETN primer in the 1-atm. section, which initiated the second plastic charge, and this delivered a standard blow to the sodium chloride. The transmitted shock set off the second PETN primer and then the third plastic charge, so that the process was repeated symmetrically in the high-pressure section. It seems therefore permissible to compare the behaviour of the first PETN and the sodium chloride charges at 1-atm. and at high initial pressure.

One can see a definito reduction in light output from the PETN at 200 atm., and more conspieuously from the salt, in which the trace dies out very quickly. Similar, but rather less marked, effects were found at 100 atm. However, it is perhaps more significant that so much light persists at all at these high initial pressures.

I thank Dr. Secly for sending me advance details of his experiments, and for his comments. I thank also Mr. Cumming for his advice, and Mr. H. Andrew and Mr. J. Logan for assistance in the experiments.

Imperial Chemical Industries, Ltd.,

$$
\text { Stewart Paterson }
$$

Nobel Division,

$$
\text { Stevenston, Ayrshire. }
$$

${ }^{1}$ Blackburn, J. H., and Seely, L. B., Nature, 194, 370 (1962).

2 Paterson, S., Nature, 167, 479 (1951).

${ }^{3}$ Paterson, S., Fifth Intern. Symp. Combustion, 672 (Reinhold, 1955).

4 Blackburn, J. H., and Seely, I. B., Nature, 202, 382 (1964).

5 Taylor, J., Detonation in Condensed Explosives, plate 10 (Oxford, 1952).

\section{Resistance Inequalities}

IT is well known that the electrical resistance tensor $r$ is symmetric in the absence of a magnetic field. It is the purpose of this communication to point out that this implies that certain inequalities exist between the diagonal and off-diagonal elements of $r$. To obtain these we note that since $r$ is symmetric it can always be diagonalized by a rotation of co-ordinate axes, and the resulting diagonal tensor will have all its diagonal elements positive, since these will be the resistances along the 'new' axes. Hence $r$, considered as a matrix, is positive-definite and this implies that inequalities between its elements must exist of the form:

$$
r_{x x} r_{y y} \geqslant r^{2} x y
$$

\section{S. Sryons}

Queen Mary College, University of London, E.1.

\section{GEOLOGY}

\section{The British Mesozoic Committee}

LAST year, a note was published in Nature ${ }^{1}$ which summarized the recommendations of an international colloquium at Luxemburg on the definition of Jurassic stages and added the views of the British Mesozoic Com- mittee on these recommendations. The stated object of this note was to give other British Mesozoic specialists the opportunity of considering the recommendations and. of expressing their opinions about them. As a result of this and of further recommendations from other national committees brought forward at a meeting of the international Mediterranean Mesozoic Committee in September 1963, the British Committee decided that further discussions were necessary. A general meeting was, therefore, arranged at the Geological Society of London on February 26. This meeting, which was attended by 65 geologists who were specializing in the Mesozoic, was intended to guide the Committee in framing its further recommendations to the international organization.

Immediately after the general meeting, the Committee agreed on the following recommendations : (1) The British Mesozoic Committee considers that, not withstanding the Statement of Principles embodied in Part 25 of the twenty-first Session of the International Geological Congress, Mesozoic stages must in practice be defined in terms of faunal zones (that is, "belts of strata, each of which is characterized by an assemblage of organic remains, of which one abundant and characteristic form is chosen as index" Marr 1898, Arkell 1933). (2) As a general principle, only the base of each stage should be regarded as fixed, preferably by reference to a specified point in a type section for the lowest zone. (3) The Rhaetian should be regarded as the topmost stage of the Triassic System, and no part of it should be included in the Jurassic. (4) The terms Lias, Dogger and Malm should be rejected as international stratigraphical units. (5) The Jurassic should be divided into Lower, Middle and Upper divisions. (6) The British Committee does not recommend the definition of named substages. (7) The British Committee does not consider that a case has been made for the recognition of the A.alenian as a separate stage. (8) The Bajocian Stage and the Middle Jurassic should be regarded as beginning with the opalinum Zone. (9) There exists a difference of opinion among British specialists, but a majority favour the inclusion of the Callovian Stage in the Upper Jurassic. (10) In the interests of achieving international stability and uniformity of nomenclature, British specialists have no objection to the eventual dropping of the term 'Portlandian' as an international stage name. (11) Many British spocialists favour the retention of the Kimmeridgian Stage in its broader sense, up to and including the pallasioides Zone. However, the British Committee recommends that only the base of this stage should be defined (as the baylei Zone) and are prepared to accept the next successive stage as the Volgian, as at present defined by the Jurassic Commission of the Stratigraphical Committee of the U.S.S.R. (12) The British Committee prefers the retention of both the Volgian and Tithonian Stages at the top of the Jurassic, and both the Ryazanian and Berriasian Stages at the bottom of the Cretaceous until such time as the Boreal and Tethyan provinces have been adequately correlated.

Postscript. The above recommendations were presented at a meeting of the International Committee near Marseille in May. They were all accepted, except that a majority favoured the retention of the Aalenian as a stage and the placing of the Callovian in the Middle Jurassic (though the objections of the British and Russian committees to this were to be forwarded to the International Congress). Also the Volgian Stage was preferred as the top division of the Jurassic, with the Tithonic (sic) to be retained only as a facies name, since it contravenes the rules of stratigraphical nomenclature.

Department of Geology,

$$
\text { D. V. AgEr }
$$

Imperial College of Science and Technology,

$$
\text { London, S.W.7. }
$$

${ }^{3}$ Ager, D. Y., Nature, 198, 1045 (1963). 